\title{
Estimation of Total Labor Costs in the Russian Economy Taking Into Account the Qualification Level of Employees
}

\author{
E. A. Edinak* \\ Institute of Economic Forecasting, Russian Academy of Sciences, Moscow, 117418 Russia \\ *e-mail: edinak_e@mail.ru \\ Received July 13, 2020; revised July 22, 2020; accepted September 8, 2020
}

\begin{abstract}
The article, which is a continuation of the study published in the previous issue of the journal, describes a methodology for assessing the total cost of labor in the economy in the context of certain groups of the employed population. In particular, the analysis of estimates of direct and indirect labor costs for three levels of qualifications of workers is carried out. Based on estimates of indirect labor costs, it is shown that the number of jobs produced by one job for workers of low, medium and high skill levels is different both within the same industry and in related industries.
\end{abstract}

Keywords: total labor costs, labor market, skill level, workplace, input-output balance, employment multipliers, forecasting

DOI: $10.1134 / \mathrm{S} 1075700721010044$

The economic and social crisis associated with the introduction of restrictive measures by states in response to the spread of coronavirus infection brought to the fore the issues of support and restoration of employment and incomes of the population. By the beginning of the recovery period of the Russian economy, the unemployment rate had grown by just over 1 percentage point: $5.8 \%$ in April 2020 compared to $4.7 \%$ in March 2020 and April 2019. This state of the labor market reflects the desire of enterprises to maintain employment even in the face of limited funds for compensation of labor costs. However, the possibility of a second and subsequent waves of the epidemic spreading could change the employment situation and cause a sharp rise in unemployment.

The postcrisis recovery of the Russian economy, employment and incomes of the population is associated with the actualization of potential sources of economic growth and the development of directions of action to achieve it. So, the government $\operatorname{plan}^{1}$ lists four key initiatives for the growth of real incomes of citizens, the restoration of effective employment, and effective demand. Two of them are associated with the creation of a system of social support measures and the implementation of social payments to the population (social treasury and targeted cash payments). Another involves the development of normative legal support for remote work of citizens, as well as the improvement of the mode of part-time employment and selfemployment (the labor market in the digital era).

\footnotetext{
${ }^{1}$ A nationwide action plan to ensure employment and income recovery, economic growth and long-term structural change, Government of the Russian Federation, Moscow, May 31, 2020.
}

Finally, for those who have lost their jobs, it is proposed to provide assistance in retraining and retraining (assistance to those who have lost their jobs). It should be noted that the implementation of this initiative depends on which industries will primarily act as drivers of economic growth in the medium and long term, since the sectoral structure of the economy determines the quantitative and qualitative, including qualification, future needs of business in the workforce. Note that industries differ not only in labor intensity, but also in their ability to create jobs in related industries. Moreover, the effect of producing additional employment depends on the qualifications of the workplace. In other words, the number of jobs created for low, medium and high skilled workers differs. This thesis is very important for understanding the consequences for the labor market and the employment sector of measures to support/develop certain industries. For example, it is necessary to determine the financial support of which industries will most ensure the creation of jobs in the economy as a whole and in individual industries. What kind of jobs based on qualifications (educational, professional, etc.) should be created to maintain and increase the number of highly productive jobs in the economy?

The list of such questions that are relevant during the recovery stage and attaining sustainable economic growth rates can be expanded. Despite their importance and severity, there is a shortage of Russian studies containing quantitative estimates of such effects.

Moreover, structural imbalances in the labor market are a limiting factor for sustainable economic growth. Sectoral, regional, professional, qualification, 
educational and other structural inconsistencies, to one degree or another characteristic of the national labor markets of most countries, entail a loss in labor productivity growth rates, a decrease in the volume of potential GDP, difficulties in finding a job and personnel (see, e.g., [1]). At the level of an individual employee, the discrepancy between his skills and the workplace creates a psychological problem when a person cannot fully realize his capabilities: his professional qualifications are not in demand by the market. All this ultimately negatively affects the quality of human capital.

The task of minimizing the structural imbalance of the labor market includes requirements not only for the accuracy of the forecast of the total demand for labor in the economy, but also for the depth of such a forecast, determined by a set of qualitative characteristics of the demand for labor. A quantitatively and qualitatively coordinated forecast will make it possible to reduce structural imbalances in the future by harmonizing the parameters of labor demand and supply.

A tool for analyzing the impact of economic policy on the employment sector and the labor market that can answer the above questions are matrices of coefficients of total labor costs (see [2]). On the basis of Russian data, the difference in industries was demonstrated both in the level of labor intensity and in the ability to produce jobs in related industries.

This study describes the methodology for assessing the total labor costs simultaneously in the context of industries (types of economic activity) and groups of occupations, aggregated into three enlarged qualification groups. These estimates allow a deeper study of the structural characteristics of the employment sector through the prism of intersectoral interactions; to understand which industries are most promising in terms of increasing the number of jobs for highly skilled workers in the economy, and which industries, on the contrary, generate jobs for low-skilled workers to a greater extent; to mitigate the problems of the personnel gap by harmonizing the qualification structure of labor supply and demand.

Employment of the population by industry and occupation group indirectly characterizes the industry in terms of the qualification structure of their labor intensity (that is, the number of employees of a certain skill level per unit of output or the final demand for the industry's products and services). The Labor Force Survey (LFS) collects information on the distribution of the number of people employed in the economy by consolidated economic activity and by major groups and subgroups (excluding small groups) of occupations ${ }^{2}$. The analysis of these data as a reflection of the current demand for certain skills in the conditions of

\footnotetext{
2 Types of economic activity are sections of OKVED 2 (All-Russian Classifier of Economic Activities OK 029-2014). Groups and subgroups of classes correspond to OK 010-2014 (ISKZ-08) (All-Russian classifier of classes-OKZ).
}

the existing production and technological structures of the economy is presented in the works $[3,4]$.

For the visibility of the results, the occupation groups were aggregated into three conditional qualification groups: high-, medium- and low-skilled work$\mathrm{ers}^{3}$. The first group, highly qualified workers, includes "Managers," "Specialists of the highest qualification level." The second group-workers of average qualification-includes groups of occupations: "Specialists of average qualification," "Employees engaged in the preparation and execution of documentation, accounting and maintenance," "Skilled workers in agriculture and forestry, fish farming and fishing," "Skilled workers in industry, construction, transport and workers of related occupations," "Plant and machine operators, assemblers and drivers." The third group, conventionally named low-skilled workers, included "Workers in the service sector and trade, protection of citizens and property," "Unskilled workers."

As of 2017, the share of highly skilled workers in the total number of employed in the Russian economy was $31 \%$ (22.5 million people), medium-skilled workers, 45\% (32.4 million people), and low-skilled workers, $27 \%$ (14.4 million people).

The largest share of highly skilled workers in the total number of employed is concentrated in the "Education" sector (22\%), in the second and third places are "Manufacturing" and "Wholesale and retail trade; repair of motor vehicles and motorcycles" ( 10.5 and $10.2 \%$, respectively); in the fourth, "Activities in the field of health and social services" (8.5\%). The largest share of workers with an average skill level was recorded in the industries "Manufacturing" (20.4\%), "Transportation and storage" (14.4\%) and "Construction" (11\%). Low-skilled workers, with a wide margin from other industries, make up a significant part of those employed in the industry "Wholesale and retail trade; repair of motor vehicles and motorcycles" (36\%).

\footnotetext{
${ }^{3}$ It should be noted that the transition from groups (subgroups) of occupations to the formation of skill groups of workers faces difficulties associated with a high level of aggregation of statistical data. Groups and subgroups of occupations are very heterogeneous in terms of the qualification composition of workers. Therefore, the assignment of groups (subgroups) of workers to a particular skill group is conditional. The problem of more accurate formation of qualification groups can only be solved by analysis at the level of initial groups. But statistics on the distribution of workers by type of economic activity are not provided even at the level of small groups. The same problem applies to economic activities. So, for example, section C "Manufacturing" includes 23 classes, which are very different from each other in a wide range of characteristics, including the qualifications of workers. The lack of more detailed information does not yet make it possible to conduct a more complete study in the context of qualification groups. However, the toolkit described here, first, can be used in relation not to qualification groups, but to groups (subgroups) of classes. Secondly, when statistics of a "lower" level appear, it allows calculations and estimates to be made for each class of types of economic activity and initial groups of occupations, aggregated at the level of skill groups.
} 
The industries differ from each other in the qualification structure of the employed, which determines the differences in the qualification structure of their labor intensity. The table shows the grouping of industries depending on the prevalence of labor costs of a particular skill level in the total labor intensity of the industry.

As you might expect, low-skilled workers are concentrated in the service industries: "Hotels and public catering establishments," "Wholesale and retail trade," "Other types of services." Two of the industries in the third group are characterized by a high level of labor intensity. In addition to them, the sectors Education (1st group) and Health care and social services (2nd group) have high labor intensity.

The largest share of highly qualified workers is in industries that make appropriate requirements for the level of training of their employees: "Professional, scientific and technical activities," "Education," "Information and communication," "Finance and insurance," etc. Intercountry comparisons based on aggregated data (9 groups of occupations and 20 industries) do not give grounds to assume the presence of critically significant imbalances in the structure of employment by industry and group of occupations in the Russian economy [3]. Population employment statistics by industry and occupation group can be used to assess the total labor costs in the context of individual occupation groups (enlarged qualification groups of workers).

Methodology for assessing total labor costs in the economy for certain groups of the employed population. Estimates of total labor costs reflect the sum of all labor costs in the economy for the production of final goods and services in a particular industry. In addition to the data on the number of employed people in each industry (direct labor costs) published by official statistics, the economy has so-called indirect labor costs, the presence of which is due to intersectoral interactions ${ }^{4}$. The sum of direct and indirect labor costs for a particular industry is the value of the total labor costs in the economy, providing the final production of this industry.

The vector of total labor costs can be calculated based on the following ratio:

$$
P=T(E-A)^{-1}=T L,
$$

where $P$ is a row vector of total labor costs per unit of final production of industries (in monetary terms); $T=\left(t_{1}, t_{2}, \ldots, t_{n}\right)$ is a row vector of sectoral labor input, calculated as the ratio of the number of employees in the industry to its output; $A=\left(a_{i j}\right)_{i, j=1, n}$ is the matrix of

\footnotetext{
${ }^{4}$ A detailed methodology for assessing the total cost of labor, as well as the main directions of using these estimates are described in [2].
}

direct costs coefficients, calculated on the basis of a symmetric input-output table of the input-output balance (IOB); $E$ is the unit matrix of dimension $n \times n$; $L=\left(l_{i j}\right)_{i, j=\overline{1, n}}$ is the matrix of total costs coefficients (Leontief matrix); $n$ is the number of industries under consideration.

With the availability of relevant data, estimates of total labor costs can be obtained in professional, gender, educational, and qualification sections. This requires information on the unit labor costs per unit of output of industries (i.e., labor intensity) for the respective groups of employees. Then formula (1) can be detailed:

$$
P^{k}=T^{k} L
$$

where $k=\overline{1, u}$ is a certain group of employees, and $u$ is the number of groups.

So, if we conduct a gender study of employment on the basis of total labor costs, then $u=2, T^{1}$ and $T^{2}$ are vector-lines of sectoral labor inputs of men and women, respectively; $P^{1}$ and $P^{2}$ are row vectors of the total labor costs of men and women, respectively, per unit of the final production of industries (in monetary terms).

If we solve the problem of assessing the total labor costs in the context of three qualification groups of workers, then $u=3, T^{1}, T^{2}$ and $T^{3}$ are vectors-lines of sectoral qualification labor inputs; $P^{1}, P^{2}$ and $P^{3}$ are the required estimates of the vectors of total labor costs in the context of groups of workers of high-, mediumand low-skill levels, respectively, per unit of the final production of industries (in monetary terms).

In addition to three vectors of total labor costs, estimates of three matrices of intersectoral labor costs can be obtained for each qualification group of workers. These matrices $\left(Z^{u}=\left(z_{i j}^{u}\right)_{i, j=\overline{1, n}}\right)$ reflect the intersectoral structure of employment of workers of a certain qualification level; element $z_{i j}^{u}$, the $u$ th matrix shows how much is employed in the industry $i$ of workers of the $u$ th skill level to ensure the production of a unit of final production (in monetary terms) of the industry $j$. Absolute values of the matrix of intersectoral labor costs for workers of the $u$ th skill level can be calculated based on the following ratio: $\hat{T}^{u} L \hat{Y}$, where $\hat{T}^{u}$ is a diagonal matrix with the sectoral labor intensity of workers of the $u$ th skill level on the main diagonal; $\hat{Y}$ is the diagonal matrix of final demand volumes on the main diagonal.

It should be noted that if estimates of total labor costs are widely used in world practice (a review of international experience is presented in [1]), then published studies with calculations of total labor costs in the context of certain groups of employees have not been met by the author of the article. 


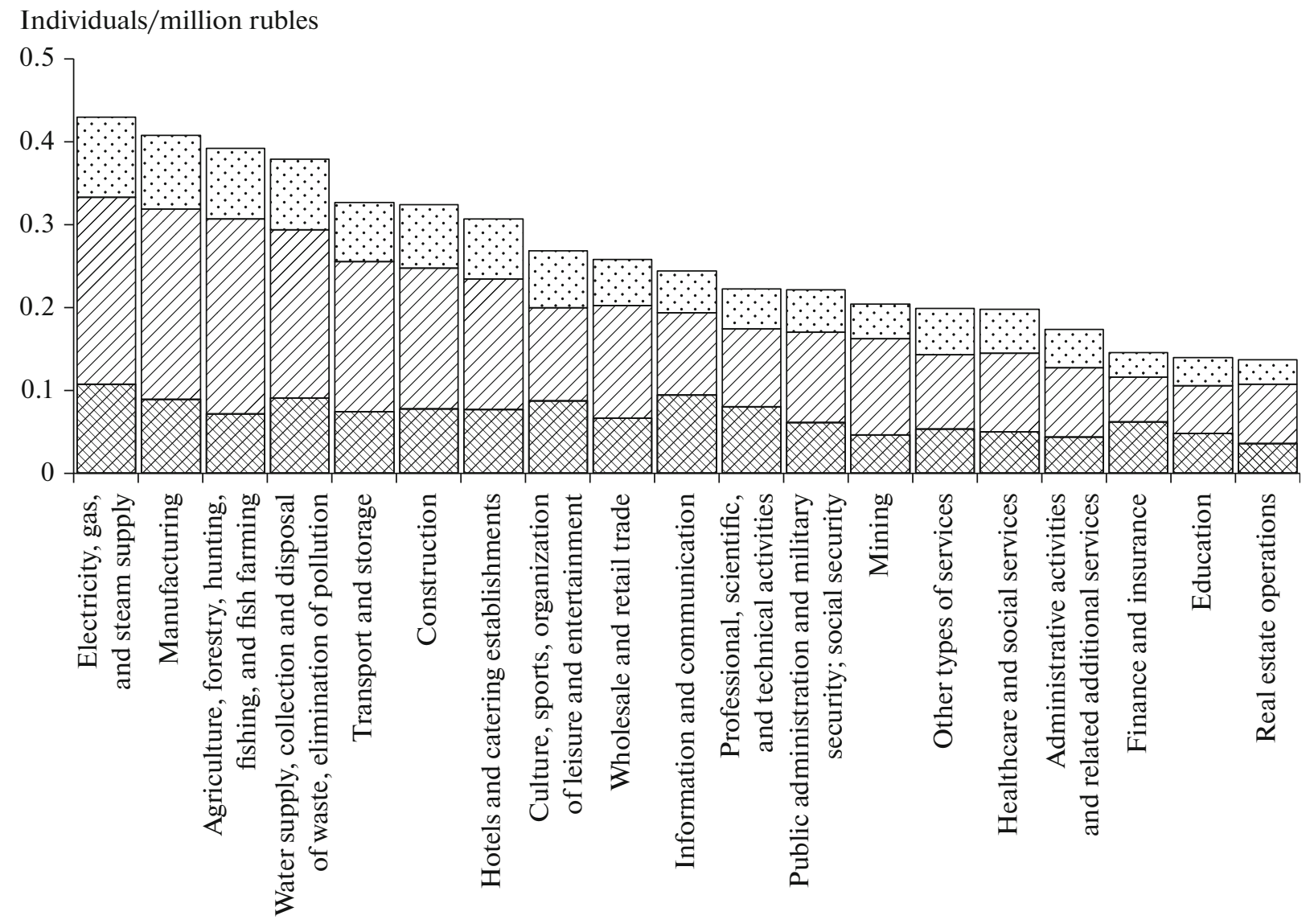

Fig. 1. Estimation of indirect labor costs in the context of three qualification groups of employees, 2017: $\otimes$ highly qualified; $\square$ workers of average skill level; $\because \cdot$ low-skilled.

Source: author's calculations based on Rosstat data.

Estimation of total labor costs in the Russian economy, taking into account the qualification level of workers. As noted above and demonstrated in [2], industries have different potential for job creation ${ }^{5}$ in economics. The size and depth of the recall ${ }^{6}$, which arises in connection with the movement of jobs in the economy, is a critical issue in assessing the impact of economic policies on the labor market. The more comprehensively this "review" is studied, the more complete understanding of the relationship between employment and the labor market with the sectoral and technological structure of the economy is being formed. The qualification structure of "recall" can be

\footnotetext{
${ }^{5}$ As in [2], in this study, jobs and employment do not differ, which is not entirely correct, but under the assumption of a constant intensity of use of jobs, this simplification does not distort the essence of the calculations.

${ }^{6}$ In the English-language literature, this "review" is called the "ripple effect," that is, a ripple effect that is associated not only with the creation of jobs in related industries as a result of growth in the output of an industry and the resulting increase in its intermediate costs, but also with an increase in income (and, accordingly, expenses) of workers in this and other industries.
}

partially (but not completely) measured using estimates of indirect labor costs based on relationship (2).

The statistical basis for calculating direct and indirect labor costs in the context of the skill groups of workers is the intersectoral balance of Rosstat (in basic prices for 2017, excluding the import component from intermediate and final consumption) and sectoral employment in the context of occupation groups (LFS data).

In Fig. 1 shows an estimate of the indirect labor costs for each industry, taking into account the qualification level of workers (calculated per million rubles of final demand for the industry's products and services).

The first four industries with the highest estimates of indirect labor costs have the highest multiplier effect: the final demand for goods and services in these industries provides the largest number of jobs in other industries. These industries belong to the real sector of the economy. This fact confirms the thesis that a sustainable recovery of the service sector affected by the pandemic and, accordingly, an increase in the income of most citizens with an average level, is impossible 
without an increase in income in the real sector [5]. The growth of income is provided, among other things, by supporting the final demand for the products of these industries, which entails not only an increase in income (and, accordingly, expenses) of their employees, but also contributes to the maintenance and expansion of the number of jobs in the service sectors.

The service industries are characterized by the average level of indirect labor costs-Transportation and storage, Hotels and catering establishments, Wholesale and retail trade-and the lowest: Operations with real estate, Education, Finance and insurance, etc.

In addition, in the total number of jobs produced by industries in the economy (per unit of final demand for products and services of industries in monetary terms), jobs for workers with a medium skill level prevail (Fig. 1). The share of these workers varies from $37 \%$ (Finance and Insurance) to $60 \%$ (Wholesale and Retail). Most likely, the result obtained can be explained by the fact that the group of workers of the average qualification level is the most numerous $(45 \%)$ in the qualification structure of the employed.

Equally curious are the estimates of the indirect labor costs for three skill groups of workers, calculated not per unit of final demand for the products and services of industries, but per one corresponding job (one employed) in the industry ${ }^{7}$ : how many jobs in the economy, for example, for highly skilled workers, are produced by one job for a highly qualified worker in the industry $i$ (multiplier effect). Calculations showed that, according to this criterion, the industry can be divided into three groups (Fig. 2).

The industries in the first group (Fig. 2a) are characterized by the greatest multiplier effect for jobs corresponding to a low skill level. For example, for one job for a low-skilled worker employed in the electricity, gas and steam supply industry, given the current technological structure of the economy, the existing interindustry relations and the share of the import component, there are almost six jobs for workers of the corresponding (i.e., low) level of qualifications in other industries. It is another matter that this industry is included in the group of industries, in the total labor intensity of which workers of average skill level prevail: $66 \%$ versus $7 \%$ of low-skilled workers (Table 1 ). That

\footnotetext{
${ }^{7}$ It should be noted separately that this calculation system does not reveal the magnitude of the current qualification imbalance in the labor market. In other words, estimates of direct and indirect labor costs in terms of qualifications are made from the side of labor demand, not its supply. Ignoring double (triple) employment in this case, the multiplier effect was calculated specifically for jobs of a certain skill level produced by one corresponding industry job (and not for workers of a certain skill level produced by one corresponding industry worker). The difference lies in the fact that in the second case it is not known whether the qualifications of the workers correspond to their position.
}

is, with an increase in production volumes, this industry will to a greater extent present demand for workers of average skill level, for whom the multiplier effect is slightly higher than one.

For comparison, in the type of activity "Extraction of minerals" the similar effect is 4.6. As in the previous case, $73 \%$ of the total labor intensity of this industry is accounted for by workers of average skill level, and in general, the labor intensity of this industry is very low. The first group also includes such industries as, for example, "Professional, scientific and technical activities," "Health and social services" or "Information and communication"; however, in general, the value of indirect labor costs for these industries is low compared to other industries in this group. In addition, these industries are characterized by the prevalence of highly skilled workers in the total labor intensity.

Thus, the first group includes industries in which there is a low proportion of low-skilled workers, which leads to a high multiplier effect of jobs for this group of workers.

The five service industries in the second group (Fig. 2b) are characterized by a higher multiplier effect for jobs for workers with an average skill level (the value of which for all industries in this group does not exceed unity). For example, there is slightly less than one intermediate-skilled worker in other industries per eligible job for an employee in the Wholesale and Retail industry. At the same time, workers with a low qualification level prevail in the structure of employed in three industries from this group. Consequently, with an increase in production volumes, industries will first of all present demand for low-skilled workers, which corresponds to a multiplier effect below 0.5 (i.e., two jobs for low-skilled workers in these industries account for less than one corresponding job in related industries) .

In the industries of the third group (Fig. 2c), the multiplier effect prevails for jobs for highly qualified workers. These include "Agriculture" and "Other types of services" (the share of highly skilled workers in these industries in the total labor intensity is $10 \%$ and $15 \%$, respectively). Consequently, in the context of production growth, these industries will increasingly present demand for workers of average skill level (Agriculture) and low-skilled workers (Other types of services), the multiplication coefficient for which is low.

Thus, estimates of the coefficients of multiplication of jobs in the context of the qualification groups of workers should not be interpreted in isolation from the size and qualification structure of employment in industries, as well as the scale of their indirect labor costs.

Estimates of indirect labor costs (see Fig. 1) and job multiplication coefficients (see Fig. 2) in the context of three qualification groups of workers can also be considered in the sectoral context: in the form of matrices of intersectoral labor costs. They provide 
Multiplication factor

(a)

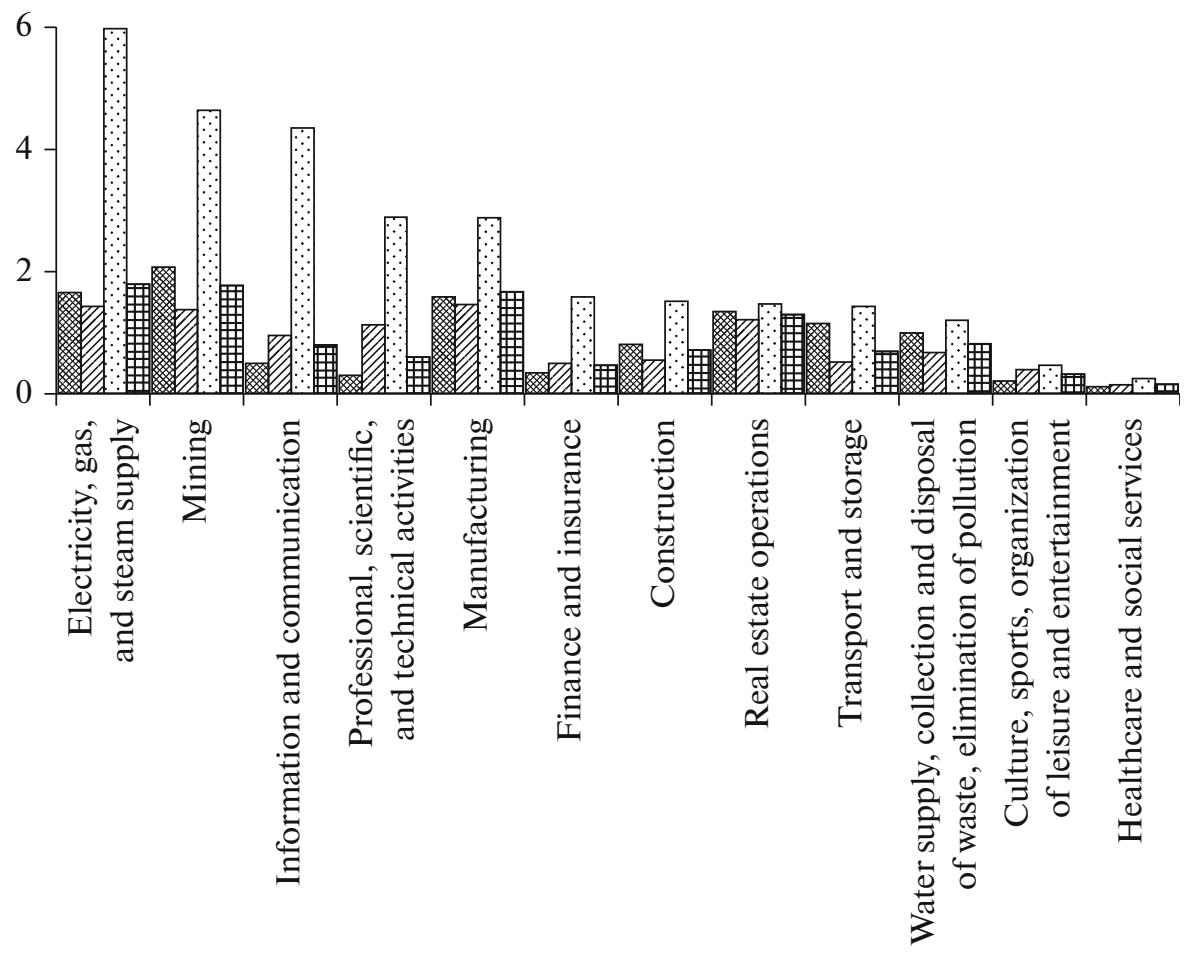

Multiplication factor

(b)

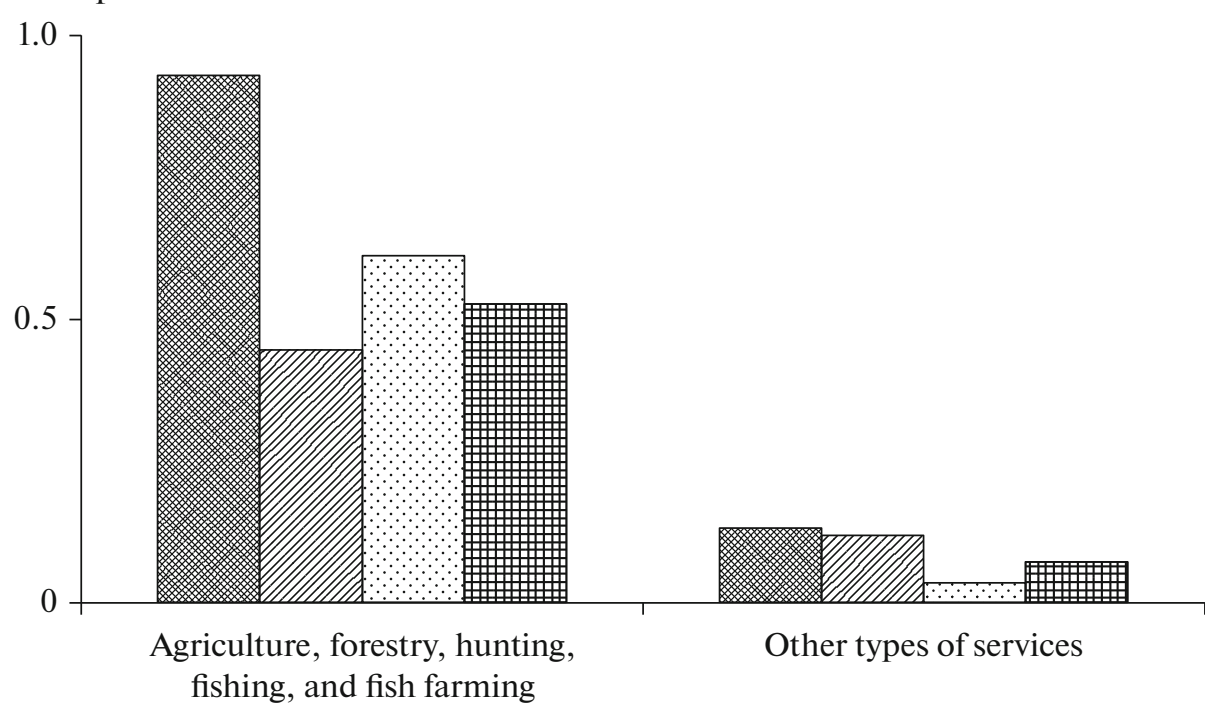

Fig. 2. The coefficient of multiplication of jobs in the context of three qualification groups of workers per 1 corresponding job in the industry, 2017: highly skilled workers; $\mathbb{Z}$ workers of average qualification; -1 low-skilled workers; $\mathbb{\text { Total }}$ Source: author's calculations based on Rosstat data.

information about which related industries are producing jobs. For example, of the six jobs for lowskilled workers in related industries per one job in the Electricity, gas and steam supply industry, most are concentrated in the Wholesale and retail trade; repair of motor vehicles and motorcycles and Administrative activities and related additional services.

Opportunities and prospects for the application of the technique. The development of certain industries has an individual impact on the labor market and on the 


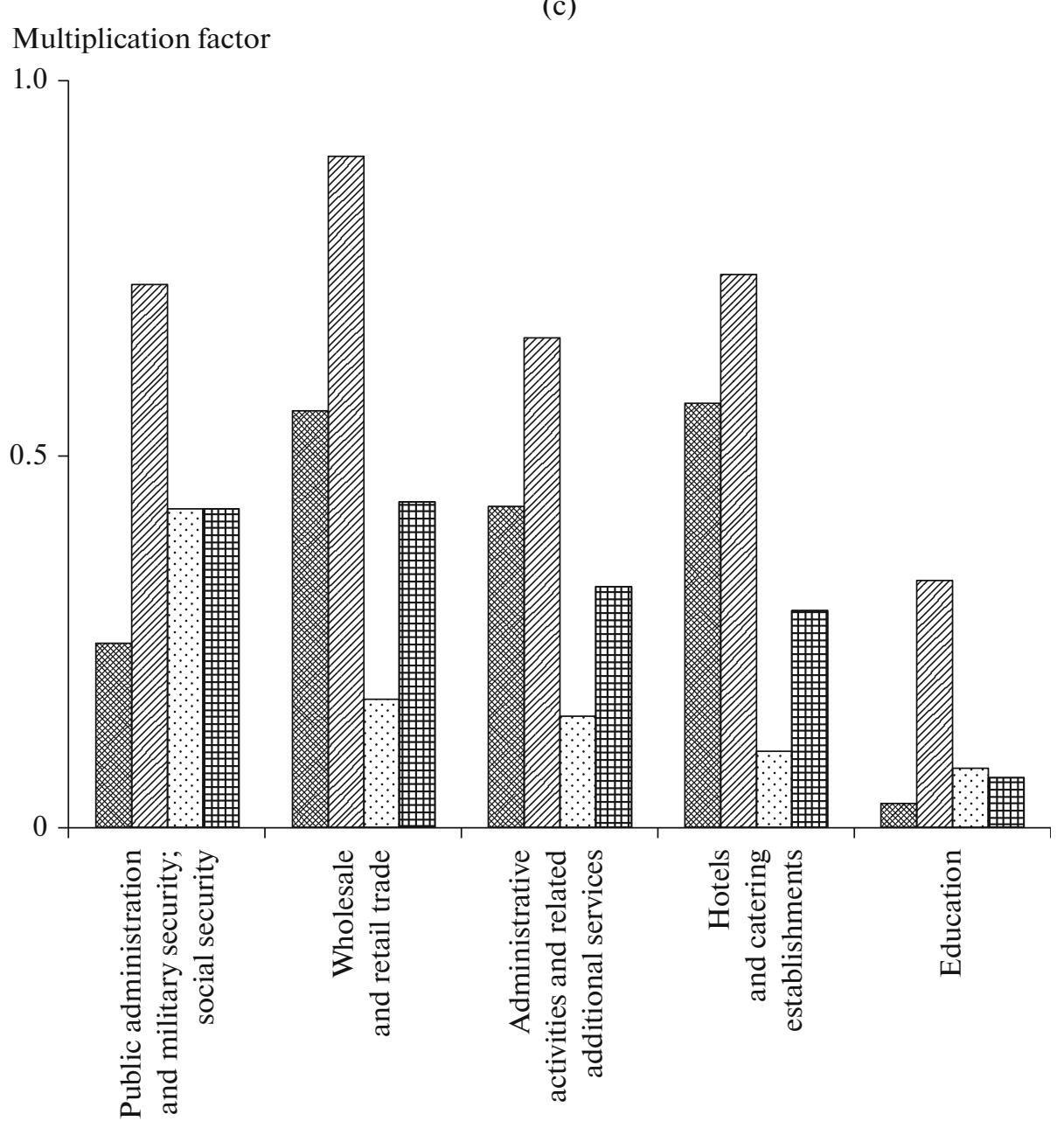

Fig. 2. (Contd.)

structure of demand for labor. The scale and structure of this response can be fully measured on the basis of total labor costs in the context of individual groups of workers.

The transformation of the structure of the economy is changing the requirements of the business for the professional skills of the workforce. In these conditions, a number of serious problems arise. Firstly, some workers in the labor market need retraining, and secondly, the existing education system may not have time to adapt to new conditions and produce specialists who are not in demand in the labor market.

The proposed toolkit and the research carried out on its basis can contribute to the harmonization of the training and retraining system and the needs of the labor market in the short and medium term. However, the calculation system presented in the article is made at the aggregated level of both industries and skill groups of workers (see footnote 3 ). In addition, for a more in-depth study and forecast of the economy's needs for personnel, detailed information is needed on the current structure of employed by industry, taking into account their level of education, specialties and specialization. Then forecasting the economy's demand for labor based on the coefficients of total labor $\operatorname{costs}^{8}$ could be as close as possible to the understanding of what should be the structure of the graduation of specialists from higher and secondary educational institutions to meet these needs. However, unfortunately, at the moment the information necessary for this is not available, which limits the wide possibilities of using the proposed tools. At the same time, the results obtained are an important addition to the analysis of the system of intersectoral interactions that has developed in the country.

\footnotetext{
${ }^{8}$ Medium and long-term forecasting of the economy's demand for labor based on the coefficients of total labor costs assumes the availability of forecast estimates of the MOB, which are developed within the framework of the balance interindustry models of the Russian Interindustry Model RIM (Russian Interindustry Model) [6] and CONTO (the model name comes from the Italian conto which translates as an account) [7].
} 
Table 1. Qualification structure of employment in industries, 2017,\% of the number of people employed in the industry

\begin{tabular}{c|c|c|c}
\hline Industry & $\begin{array}{c}\text { Labor intensity, } \\
\text { people/mln rub. } \\
\text { industry output }\end{array}$ & $\begin{array}{c}\text { Highly qualified } \\
\text { workers }\end{array}$ & $\begin{array}{c}\text { Medium skilled } \\
\text { workers }\end{array}$ \\
$\begin{array}{c}\text { Low-skilled } \\
\text { workers }\end{array}$ \\
\hline
\end{tabular}

1. Industries with a predominance of highly qualified workers in the structure of employed

Professional, scientific and technical activities

\begin{tabular}{l|l}
0.37 & 73 \\
2.11 & 71 \\
0.31 & 62 \\
0.32 & 59 \\
0.88 & 50 \\
0.52 & 48
\end{tabular}

$73 \quad 23$

71

Education

Information and communication

Finance and insurance

Culture, sports, organization of leisure and entertainment

Public administration and military security; social

Security

2. Industries with a predominance of medium-skilled workers in the structure

Transport and storage

Mining

Agriculture, forestry, hunting, fishing and fish farming

0.48

0.12

14

0.75

19

Construction

Electricity, gas and steam supply

Water supply, collection and disposal of waste, elimination of pollution

Manufacturing industries

Real estate operations

Healthcare and social services

0.40

0.24

0.47

0.25

0.11

1.39

23
8

34

35

33

29

\begin{tabular}{r|r}
33 & 4 \\
8 & 20 \\
4 & 4 \\
35 & 6 \\
33 & 17 \\
29 & 23
\end{tabular}

\section{4}

20

4

6

17

23

\begin{tabular}{l|l}
76 & 11
\end{tabular}

73

8

19

11

7

15

13

19

16

50

Households as employers

Hotels and catering establishments

Other types of services

0.05

1.06

2.79

0.54

Administrative activities and related additional services

Wholesale and retail trade

0.59

the structure of employed

Source: LFS data.

The needs of industries for a workforce of different skill levels in the reporting period may not be optimal (for example, due to a low technological level of development of industries or a high current share of imports). Then, leaving them unchanged in the forecast period, the model will reproduce structural imbalances. But the capabilities of the toolkit can be expanded due to hypotheses about the change over time in the qualification structure of the needs of industries for employment under the influence of automation or growth in investment activity, which entail an intensification of the process of replacing labor with capital (which is relevant for the medium and to a greater extent the long term). Then, for certain industries, a certain target qualification structure of employed people can be set, for example, typical for developed countries.

The forecast of demand for labor of various skill levels on the basis of the proposed approach also makes it possible to more reasonably approach the development of the migration policy of the state, to assess the needs of the Russian economy in foreign labor migrants, and, accordingly, to the formation of target values for the volume and qualification structure of the immigration flow in the future. It should be borne in mind that the LFS statistics do not include labor migrants, who constitute a very significant part of the labor force represented in the labor market. Industry statistics on the presence of foreign labor in the Russian labor market would significantly expand the analytical capabilities of the model.

The study of the sectoral and qualification (by occupation groups) structure of labor demand is also important because different groups of workers in different industries have a differentiated level of wages, different propensities and patterns of consumption. Taking this into account, the proposed approach allows a more in-depth study of the consequences of changes in the demand for labor of various skill levels 
in terms of the potential for growth in the volume and changes in the structure of population consumption.

\section{CONFLICT OF INTEREST}

The authors declare that they have no conflicts of interest.

\section{REFERENCES}

1. BCG, Mass Uniqueness. A Global Challenge in Competition for Talent, August (2019). https://www.bcg.com/ru-ru/perspectives/228999.

2. E. A. Edinak, "Estimating total labor input for supporting informed economic policy decisions," Stud. Russ. Econ. Dev. 31, 655-662 (2020).

3. E. A. Edinak, "Effect of structural changes in the economy on the dynamics of jobs," EKO, No. 6, 131-148 (2020).
https://doi.org/10.30680/ESO0131-7652-2020-6-131148

4. A. A. Shirov and V. V. Potapenko, "Labor market and the quality of human capital," EKO, No. 2, 18-34 (2018).

5. A. G. Aganbegyan, A. N. Klepach, B. N. Porfiryev, M. N. Uzyakov, and A. A. Shirov, "Post-pandemic recovery: The Russian economy and the transition to sustainable social and economic development," Stud. Russ. Econ. Dev. 31, 599-605 (2020).

6. A. A. Shirov and A. A. Yantovskii, "RIM interindustry macroeconomic model: Development of instruments under current economic conditions," Stud. Russ. Econ. Dev. 28, 241-252 (2017).

7. A. A. Shirov and A. A. Yantovsky, "Input-output macroeconomic model as the core of complex forecasting calculations," Stud. Russ. Econ. Dev. 25, 225-234 (2014). 